\title{
Series temporales de variables hidrobiológicas en un estuario tropical (Brasil)
}

\author{
Hydrobiological time series in a tropical estuary (Brazil) \\ Carlos E. Noriega ${ }^{1,2}$, Katia Muniz ${ }^{1,2}$, Manuel J. Flores-Montes ${ }^{1,2}$, Silvio J. Macêdo ${ }^{1,2}$, \\ Moacyr Araujo ${ }^{1,3}$, Fernando A. Feitosa ${ }^{1,4}$ y Sirleys R. Lacerda ${ }^{1,4}$ \\ ${ }^{1}$ Departamento de Oceanografia, Universidade Federal de Pernambuco. Avenida Arquitetura s/n, \\ Cidade Universitária, CEP: 50670-901, Recife, Brasil \\ ${ }^{2}$ Laboratorio de Oceanografia Química, Universidade Federal de Pernambuco. Avenida Arquitetura s/n, \\ Cidade Universitária, CEP: 50670-901, Recife, Brasil \\ ${ }^{3}$ Laboratorio de Oceanografia Física, Universidade Federal de Pernambuco. Avenida Arquitetura s/n, \\ Cidade Universitária, CEP: 50670-901, Recife, Brasil \\ ${ }^{4}$ Laboratorio de Fitoplancton, Universidade Federal de Pernambuco. Avenida Arquitetura s/n, \\ Cidade Universitária, CEP: 50670-901, Recife, Brasil \\ carlos.delnor@gmail.com
}

\begin{abstract}
This paper presents a hydrobiological time series at Barra de Jangadas estuary in Northeastern Brazil. Studies were carried out during seven consecutive days from a spring to a neap tide, in one fixed station during the dry (January) and rainy (July) seasons, in 2001. The meteorology (rainfall, evaporation, wind intensity), hydrology (temperature, salinity, $\mathrm{pH}$, dissolved oxygen-DO and relative saturation, $\mathrm{BOD}_{5}$, nutrients $\left(\mathrm{NH}_{3}{ }^{+} \mathrm{NH}_{4}, \mathrm{NO}_{2}, \mathrm{NO}_{3}{ }^{-}, \mathrm{PO}_{4}^{-3}, \mathrm{SiO}_{2}\right)$ ), bathymetry, current intensity and, chlorophyll- $a$, were studied. The principal component analysis (PCA) explained $80 \%$ of the total variance showing an inverse relationship between nutrients and DO, salinity and $\mathrm{pH}$. This analysis showed a positive correlation between low tide and nutrients, indicating anthropogenic pollution. The water temperature presented low seasonal variation, similar to chlorophyll- $a$, which presented values over $20 \mathrm{mg} \mathrm{m}^{-3}$, characterizing a eutrophic environment. Higher salt concentrations were registered during the dry season with no vertical stratification. DO varied significantly in both seasons. Total dissolved inorganic nitrogen and dissolved inorganic Phosphorus values in July were in general 2 to 5 times higher than values registered in January, respectively. The average N/ P ratio varied from 35:1 in January to 8:1 in July, being both phosphate and nitrogen limiting for phytoplankton growth. Night/day differences showed that in January, ammonia decreased in higher proportion than the other nitrogen compounds indicating assimilation by the autotrophic organisms during the day.
\end{abstract}

Key words: Nutrients, dissolved oxygen, Barra de Jangadas, eutrophication
Resumen.- Este trabajo muestra los resultados de series temporales en el estuario de Barra de Jangadas en el Noreste de Brasil. El estudio fue realizado durante siete días consecutivos desde una marea de sicigia a una de cuadratura, en una estación fija durante el periodo seco (enero) y lluvioso (julio), en 2001. Se analizaron parámetros meteorológicos (precipitación pluviométrica, evaporación, intensidad de los vientos), hidrológicos (temperatura, salinidad, $\mathrm{pH}$, oxígeno disuelto-OD y tasa de saturación, $\mathrm{DBO}_{5}$, nutrientes $\left(\mathrm{NH}_{3}{ }^{+} \mathrm{NH}_{4}\right.$, $\left.\mathrm{NO}_{2}^{-}, \mathrm{NO}_{3}, \mathrm{PO}_{4}^{-3}, \mathrm{SiO}_{2}\right)$ ), batimetría, intensidad de las corrientes y clorofila- $a$. El análisis de componentes principales (ACP), explicó el $80 \%$ de la varianza total, mostrando una relación inversa entre nutrientes y $\mathrm{OD}$, salinidad y $\mathrm{pH}$. Este análisis mostró una correlación positiva entre la bajamar y los nutrientes, indicativo de polución de origen antropogénica. La temperatura del agua varió poco estacionalmente, similar a la clorofila- $a$ que caracterizó un ambiente eutrófico con valores superiores a $20 \mathrm{mg} \mathrm{m}^{-3}$. Mayores concentraciones de sal ocurrieron en el mes estival y sin mostrar estratificación vertical. El oxígeno disuelto varió significativamente entre ambos períodos. Los valores totales de nitrógeno y fósforo inorgánico disuelto en julio fueron en promedio 2 y 5 veces superiores a los de enero, respectivamente. Las medias de N:P variaron de 35:1 en enero a 8:1 en julio, siendo ambos, el fosfato y el nitrógeno limitantes para el crecimiento del fitoplancton. Diferencias día/noche evidenciaron que, en enero, el amonio decreció en mayor proporción que el resto de los compuestos nitrogenados, indicativo de la asimilación por los organismos autotróficos durante el día.

Palabras clave: Nutrientes, oxígeno disuelto, Barra de Jangadas, eutroficación 


\section{Introducción}

Los sistemas estuarinos son los principales abastecedores de nutrientes para la región costera, debido a que reciben y concentran el material originado en su cuenca de drenaje, y pueden también recibir aportes significativos por acción antropogénica. Todo ese aporte de nutrientes (materia prima imprescindible para la producción primaria) coloca los estuarios entre los sistemas más productivos del mundo, con altas tasas de producción primaria y de biomasa autotrófica y heterotrófica (Braga et al. 2000, Pereira Filho et al. 2003). En función del aumento de la densidad de población humana en la zona costera, los estuarios pueden sufrir varios impactos con la entrada de efluentes domésticos, industriales o agrícolas. La geomorfología de estas áreas asociadas con los regímenes de marea y de la descarga fluvial genera patrones de circulación distintos para cada estuario, pudiendo estos actuar como filtros o como exportadores de materia (orgánica e inorgánica) para la zona costera adyacente.

El estuario de Barra de Jangadas, formado por los ríos Jaboatão y Pirapama está situado a $20 \mathrm{~km}$ al sur de la ciudad de Recife ( $8^{\circ} 14^{\prime} \mathrm{S}$ y $34^{\circ} 55^{\prime} \mathrm{W}$ ), Brasil, con una área de aproximadamente $13 \mathrm{~km}^{2}$, una profundidad media de 2,5 m y una anchura máxima de $250 \mathrm{~m}\left(\sim 32500 \times 10^{3}\right.$ $\mathrm{m}^{3}$ ). Sus longitudes alcanzan $8 \mathrm{~km}$ a montante. Estos dos ríos drenan un área de $\sim 1000 \mathrm{~km}^{2}$ hasta desembocar en el
Océano Atlántico, con caudales medios de 2,1 y 9,4 $\mathrm{m}^{3} \mathrm{~s}^{-1}$ para el Jaboatão y Pirapama, respectivamente (CPRH, 2001) (Fig. 1). Las corrientes en el estuario pueden alcanzar valores de 1,0 a $1,2 \mathrm{~m} \mathrm{~s}^{-1}$ en períodos de sicigia, principalmente en el estadio de vaciante (Coutinho 1997). Las mareas son semidiurnas y presentan rangos promedios de altura de 1,3 $\mathrm{m}$ en los periodos de cuadratura, y 1,8 m, en los periodos de sicigia, con una carrera de marea de 1,7 m (Araujo et al. 1999). Este sistema es bien heterogéneo, siendo clasificado como estuario tipo 1, y con ausencia de estratificación vertical (Araujo et al. 1999). Las masas de agua que entran por la boca del estuario muestran características típicas de aguas oligotróficas (Branco et al. 2002). Noriega et al. (2005) observó que durante el mes de julio, 38\% de la agua de rio se infiltra en el mar durante un ciclo mareal y, la tasa de renovación del agua $\left(\mathrm{T}_{50 \%}\right)$ en cada ciclo mareal fue de 1,3 dias. El litoral afectado posee clima tropical caliente y húmedo del tipo As', según la terminología de Köppen (Peel et al. 2007) caracterizada por presentar temperatura anual elevada de aproximadamente $25,5^{\circ} \mathrm{C}$ y precipitación anual superior a $2000 \mathrm{~mm}$ con dos estaciones: un período seco (septiembre a febrero) que está determinado por la evaporación superior a la precipitación, y un período lluvioso (marzo a agosto) cuando la evaporación es inferior a la precipitación (Araujo et al. 1999).

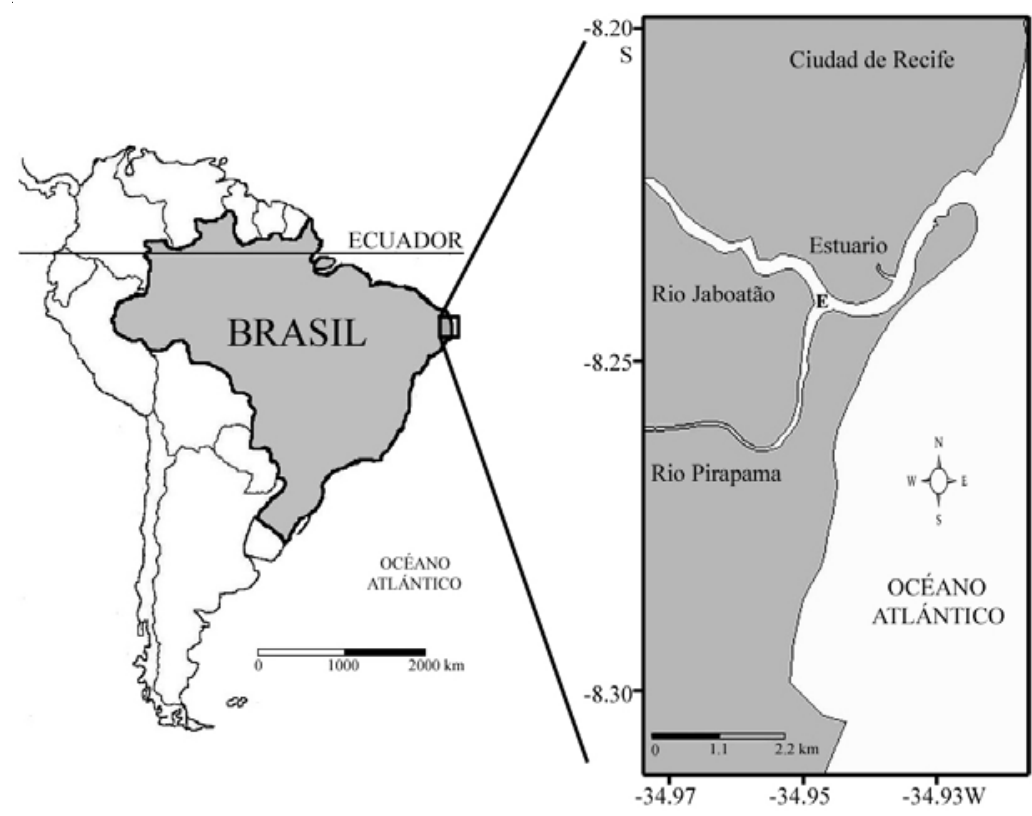

Figura 1

Mapa del área de estudio, indicando la estación de muestreo (E)

Map of the study area, indicating the sampling station (E) 
La actividad económica dominante se caracteriza por la pesca artesanal, principalmente la extracción de moluscos y crustáceos. En las márgenes de los ríos se encuentran también bares, hoteles, residencias, clubes de yates y viveros de cultivos de peces marinos y estuarinos. Dentro de las actividades industriales, se destaca la agroindustria de la caña de azúcar con sus efluentes, uno de los cuales, el ‘vinhoto’, es descargado por las fábricas existentes en las márgenes de los ríos. Este subproducto es usado en la fertilización de la caña de azúcar, lo que ciertamente incide en la calidad del agua receptora (CPRH, 2001).

La población en la cuenca hidrográfica (1,5 x $10^{6}$ habitantes), con una densidad demográfica en las proximidades del sistema estuarino de 1000 hab. km-2 (IBGE, 2000), representa un factor importante que puede influenciar de manera negativa la calidad del sistema receptor, tomando en cuenta que la mayoría de los residuos líquidos domésticos son descargados directamente a los ríos sin tratamiento previo.

Debido a la localización y a la importancia que este sistema representa para el litoral, diversos investigadores desarrollaron trabajos en la década de los años 60, destacándose los de Okuda \& Nóbrega (1960), con diversos estudios sobre la calidad del agua. A partir de esa época y por más de tres décadas este sistema no fue estudiado y, sólo a partir de la segunda mitad de los años noventa, los trabajos fueron retomados, con los estudios de Coutinho (1997), Araujo et al. (1999), Branco et al. (2002) y, recientemente, Lacerda (2004).

Para conocer la influencia de los dos ríos (Pirapama y Jaboatão), que desembocan en el estuario de Barra das Jangadas, en relación a la materia orgánica, flujo de nutrientes y déficit de oxígeno disuelto, se investigó principalmente en la zona de mezcla, a través de series temporales estacionales (enero-julio), períodos astronómicos (sicigia-cuadratura), estadios de mareas (bajamar, flujo, pleamar y reflujo), de horario (día-noche) y espacial (superficie-fondo).

\section{Material y métodos}

\section{Metodología de muestreo}

La metodología de muestreo consistió en demarcar una estación fija en la confluencia de los dos ríos (Jaboatão y Pirapama). En este punto fueron tomadas muestras hidrológicas durante una semana, totalizando una serie temporal secuencial, desde una marea de sicigia a una de cuadratura, en intervalos de 3 horas (marea alta, reflujo, marea baja, y flujo). Las muestras fueron tomadas en tres profundidades (superficie, medio y fondo), en el período seco (enero, 2001), y en el período lluvioso (julio, 2001), mediante una botella de Nansen para las determinaciones del oxígeno disuelto, salinidad, $\mathrm{pH}, \mathrm{DBO}_{5} \mathrm{y}$ nutrientes (nitrito, nitrato, amonio, fosfato y silicato). Las muestras para la determinación de $\mathrm{DBO}_{5}$ y nutrientes fueron tomadas de 6 en 6 horas en las mareas alta y baja.

\section{Metodologías de análisis}

La salinidad fue medida mediante el método de MohrKnudsen, descrito por Strickland \& Parsons (1972). El potencial hidrogeniónico $(\mathrm{pH})$ fue determinado con un pH-metro Beckman, tipo Zeromatic II. Se determinó la concentración de oxígeno disuelto $\left(\mathrm{mL} \mathrm{L}^{-1}\right)$ por el método de Winkler, descrito por Strickland \& Parsons (1972) y Grasshoff et al. (1983) y, su tasa de saturación (\%) fue obtenida utilizando las Tablas Oceanográficas Internacionales (UNESCO 1986).

La demanda bioquímica de oxígeno $\left(\mathrm{DBO}_{5}\right)\left(\mathrm{mg} \mathrm{L}^{-1}\right)$ fue medida siguiendo el método descrito por APHA (1985), utilizando una incubadora, a una temperatura de $20^{\circ} \mathrm{C}$, durante cinco días.

Las sales nutrientes (ì mol L-1), fueron analizados de acuerdo con las técnicas descritas por Strickland \& Parsons (1972), y el silicato de acuerdo con Grasshoff et al. (1983). Las mediciones de la intensidad de la corriente fueron realizadas con un correntómetro Zeromatic SD 6000. Las muestras para analizar la clorofila- $a$ fueron tomadas en superficie con botellas tipo Van Dorn de $1 \mathrm{~L}$ de capacidad, siendo la clorofila- $a$ determinada por espectrofotometría, y calculada por la fórmula de Strickland \& Parsons (1965), descritos detalladamente en Texeira (1973).

Se realizaron las pruebas $\mathrm{F}$, y t de Student para determinar estadísticamente diferencias significativas entre las concentraciones de las magnitudes y las diferentes categorías observadas como: Estación del año (verano e invierno correspondientes a enero y julio respectivamente), período de la marea (sicigia y cuadratura), estadio de la marea (bajamar, flujo, pleamar y reflujo), estrato de profundidad (superficie y fondo), y horario (día y noche).

Adicionalmente se realizó un análisis de componentes principales (ACP) según Massart et al. (1998) para las principales categorías consideradas. En este análisis, no fue considerada en la matriz, la transparencia del agua, debido al pequeño número de datos obtenidos en el área. En algunos momentos no fue posible detectar la transparencia del agua en razón del horario de muestreo. En este análisis solo fueron considerados los valores de superficie y de fondo, descartándose la profundidad media, debido a la poca profundidad en la mayoría de los estadios de marea. 
Valores mensuales y diarios de precipitación, evaporación, temperatura promedio del aire y velocidad de los vientos predominantes para el año 2001, fueron obtenidos del INMET (Instituto Nacional de Meteorología del Ministerio de la Agricultura).

\section{Resultados}

Los resultados de los parámetros estudiados se presentan en la Tabla 1.

Durante enero la precipitación sumó 58,70 mm, en comparación a julio donde fueron registrados 432,40 mm.
La evaporación en enero registró 226,60 mm siendo superior a la de julio, con 90,60 mm. Los vientos, en los días de muestreo variaron entre 1,0 y $5,0 \mathrm{~m} \mathrm{~s}^{-1}$, siendo superiores en enero, y también en el período de cuadratura para ambos meses, condición histórica típica de los vientos en esta región. (Fig. 2a,b).

La profundidad local mostró valores similares entre las medias aritméticas y en sus máximos; sin embargo, el valor mínimo en julio fue más del doble que en enero (Fig. 3a,b) (Tabla 1).

Tabla 1

Valores de los parámetros estadísticos básicos medidos en el estuario de Barra de Jangadas, en 2001

Hydrobiology basic statistics at Barra de Jangadas estuary, in 2001

\begin{tabular}{|c|c|c|c|c|c|c|}
\hline Mes & Parámetro & $\mathrm{n}$ & Promedio & D.E. & Mínimo & Máximo \\
\hline \multicolumn{7}{|c|}{ Enero } \\
\hline & Prof. local (m) & 54 & 3,51 & 0,86 & 1,40 & 5,20 \\
\hline & Transparencia (m) & 19 & 0,77 & 0,24 & 0,50 & 1,41 \\
\hline & Clorofila- $a\left(\mathrm{mg} \mathrm{m}^{-3}\right)$ & 51 & 34,04 & 33,21 & 8,12 & 158,60 \\
\hline & Velocidad $\left(\mathrm{m} \mathrm{s}^{-1}\right)$ & 108 & 0,53 & 0,12 & 0,26 & 0,79 \\
\hline & Temperatura $\left({ }^{\circ} \mathrm{C}\right)$ & 105 & 28,10 & 0,78 & 26,40 & 30,40 \\
\hline & Salinidad (ppm) & 105 & 20,14 & 11,54 & 1,72 & 35,56 \\
\hline & Oxígeno disuelto $\left(\mathrm{mL} \mathrm{L}^{-1}\right)$ & 105 & 4,03 & 1,04 & 1,81 & 7,96 \\
\hline & Tasa saturación (\%) & 105 & 82,47 & 24,24 & 34,25 & 160,37 \\
\hline & $\mathrm{DBO}_{5}\left(\mathrm{mg} \mathrm{L}^{-1}\right)$ & 51 & 0,99 & 1,29 & 0,01 & 5,05 \\
\hline & $\mathrm{pH}(\mathrm{pH})$ & 55 & 7,70 & 0,50 & 6,75 & 8,30 \\
\hline & Amonio $\left(\mu \mathrm{mol} \mathrm{L}^{-1}\right)$ & 51 & 1,15 & 2,04 & 0,00 & 8,36 \\
\hline & Nitrito $\left(\mu \mathrm{mol} \mathrm{L}^{-1}\right)$ & 51 & 0,49 & 0,46 & 0,00 & 1,79 \\
\hline & Nitrato $\left(\mu \mathrm{mol} \mathrm{L}^{-1}\right)$ & 50 & 3,55 & 2,67 & 0,66 & 9,10 \\
\hline & $\mathrm{N}$ total $\left(\mu \mathrm{mol} \mathrm{L}^{-1}\right)$ & 51 & 5,12 & 4,91 & 0,31 & 19,21 \\
\hline & Fosfato $\left(\mu \mathrm{mol} \mathrm{L}^{-1}\right)$ & 51 & 0,28 & 0,23 & 0,01 & 1,27 \\
\hline & $\mathrm{N}: \mathrm{P}$ & 51 & 35,28 & 115,04 & 1,56 & 824,64 \\
\hline & Silicato $\left(\mu \mathrm{mol} \mathrm{L}^{-1}\right)$ & 51 & 67,89 & 60,06 & 12,15 & 245,24 \\
\hline \multicolumn{7}{|c|}{ Julio } \\
\hline & Prof. local (m) & 54 & 3,91 & 0,61 & 3,00 & 5,20 \\
\hline & Transparencia (m) & 21 & 0,54 & 0,17 & 0,40 & 1,00 \\
\hline & Clorofila- $a\left(\mathrm{mg} \mathrm{m}^{-3}\right)$ & 52 & 20,85 & 13,17 & 7,73 & 56,70 \\
\hline & Velocidad $\left(\mathrm{m} \mathrm{s}^{-1}\right)$ & 98 & 0,45 & 0,15 & 0,06 & 0,85 \\
\hline & Temperatura $\left({ }^{\circ} \mathrm{C}\right)$ & 108 & 26,59 & 0,70 & 25,20 & 28,00 \\
\hline & Salinidad (ppm) & 108 & 10,41 & 12,04 & 0,27 & 33,73 \\
\hline & Oxígeno disuelto $\left(\mathrm{mL} \mathrm{L}^{-1}\right)$ & 108 & 2,62 & 1,56 & 0,08 & 6,79 \\
\hline & Tasa saturación (\%) & 108 & 51,52 & 33,83 & 1,44 & 144,49 \\
\hline & $\mathrm{DBO}_{5}\left(\mathrm{mg} \mathrm{L}^{-1}\right)$ & 56 & 0,61 & 1,78 & 0,01 & 10,02 \\
\hline & $\mathrm{pH}(\mathrm{pH})$ & 92 & 7,30 & 0,53 & 6,12 & 8,84 \\
\hline & Amonio $\left(\mu \mathrm{mol} \mathrm{L}^{-1}\right)$ & 64 & 3,80 & 2,92 & 0,05 & 9,11 \\
\hline & Nitrito $\left(\mu \mathrm{mol} \mathrm{L}^{-1}\right)$ & 64 & 0,84 & 0,41 & 0,13 & 1,78 \\
\hline & Nitrato $\left(\mu \mathrm{mol} \mathrm{L}^{-1}\right)$ & 64 & 5,41 & 2,83 & 0,33 & 12,55 \\
\hline & $\mathrm{N}$ total $\left(\mu \mathrm{mol} \mathrm{L}^{-1}\right)$ & 64 & 10,05 & 4,45 & 3,02 & 18,00 \\
\hline & Fosfato $\left(\mu \mathrm{mol} \mathrm{L}^{-1}\right)$ & 64 & 1,40 & 0,84 & 0,35 & 3,26 \\
\hline & $\mathrm{N}: \mathrm{P}$ & 64 & 8,44 & 3,21 & 2,57 & 18,68 \\
\hline & Silicato $\left(\mu \mathrm{mol} \mathrm{L}^{-1}\right)$ & 64 & 149,64 & 139,84 & 18,57 & 476,04 \\
\hline
\end{tabular}


A

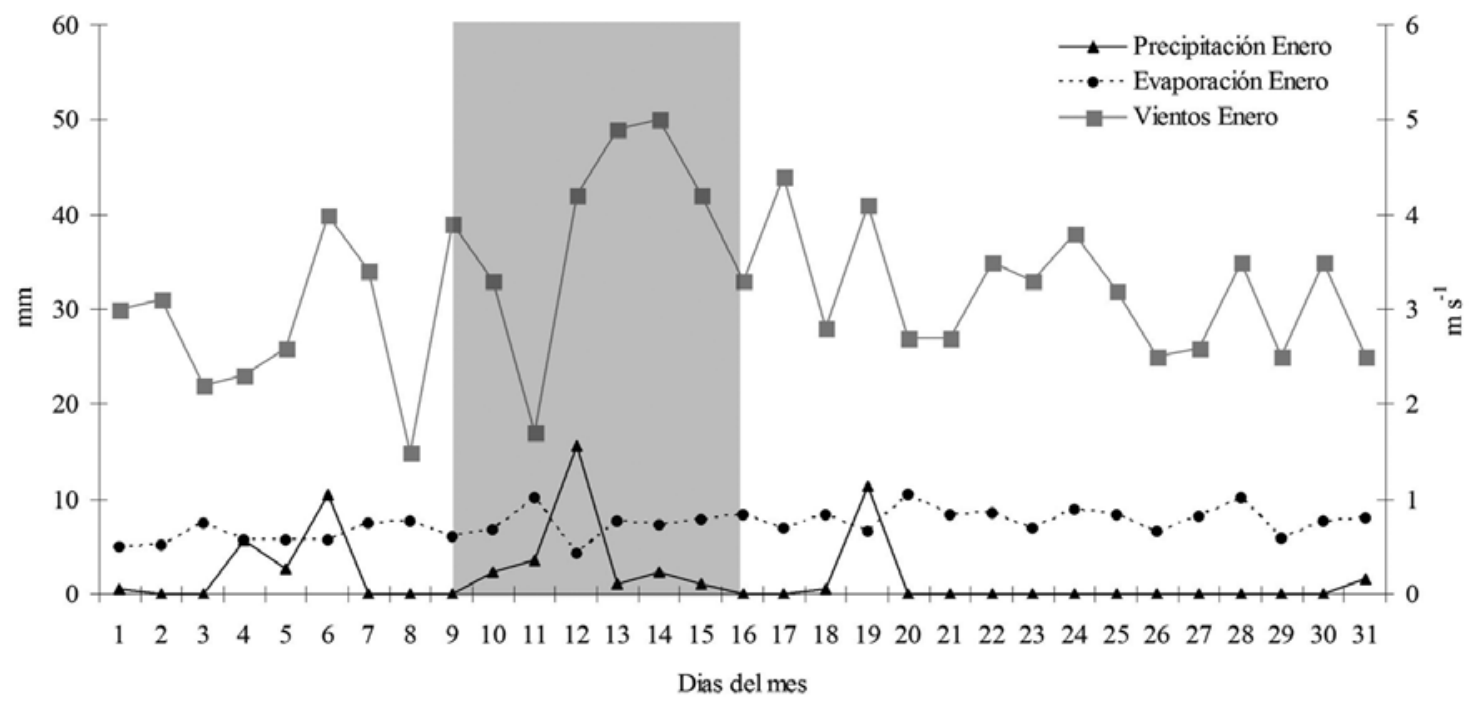

B

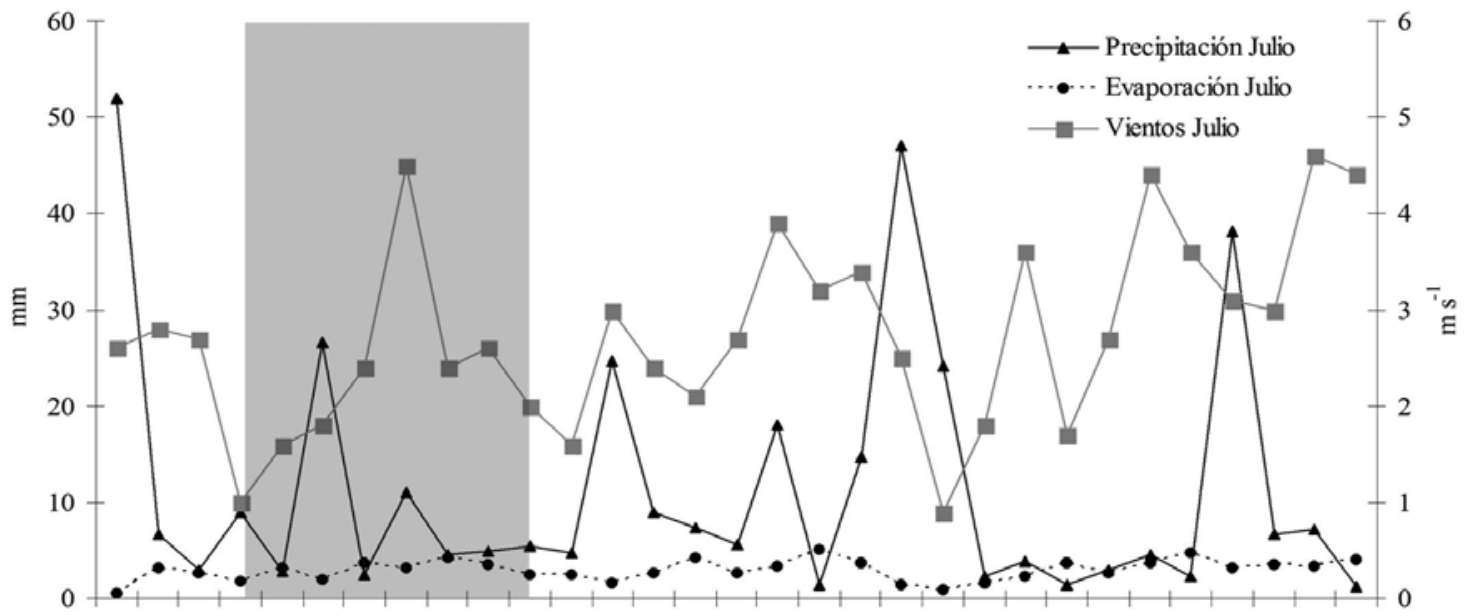

$\begin{array}{lllllllllllllllllllllllllllllll}1 & 2 & 3 & 4 & 5 & 6 & 7 & 8 & 9 & 10 & 11 & 12 & 13 & 14 & 15 & 16 & 17 & 18 & 19 & 20 & 21 & 22 & 23 & 24 & 25 & 26 & 27 & 28 & 29 & 30 & 31\end{array}$

Dias del mes

Figura 2

Variación climatológica durante el periodo de muestreo en el municipio de Jaboatao

Climatologic variation during the period of sampling in the Jaboatão suburb

La transparencia media del agua fue inferior a 1,0 m durante el período observado, con valores mayores en enero (Tabla 1).

La salinidad mostró valores mayores en enero, siendo la amplitud entre ambos meses de 9,73 unidades (Tabla 1). El valor máximo se registró en el mes estival y el menor en el lluvioso. Los valores obtenidos a través de la prueba de correlación (Pearson, á=0,05), entre la salinidad diaria y el caudal de los rios, mostraron valores significativamente diferentes de $0(-0,958 ;-0,694)$ para enero y julio, respectivamente. Las series temporales muestran que los valores fueron mayores en sicigia que en cuadratura, sin estratificación. Los valores registrados de acuerdo con el modelo de Hansen \& Rattray (1966) (äSal $\left.=\mathrm{S}_{\text {fondo }}-\mathrm{S}_{\text {superficie }}\right) / \mathrm{S}_{\text {media }}$, para sicigia y cuadratura fueron inferiores a $10^{-1}$, caracterizando el área estudiada sin 

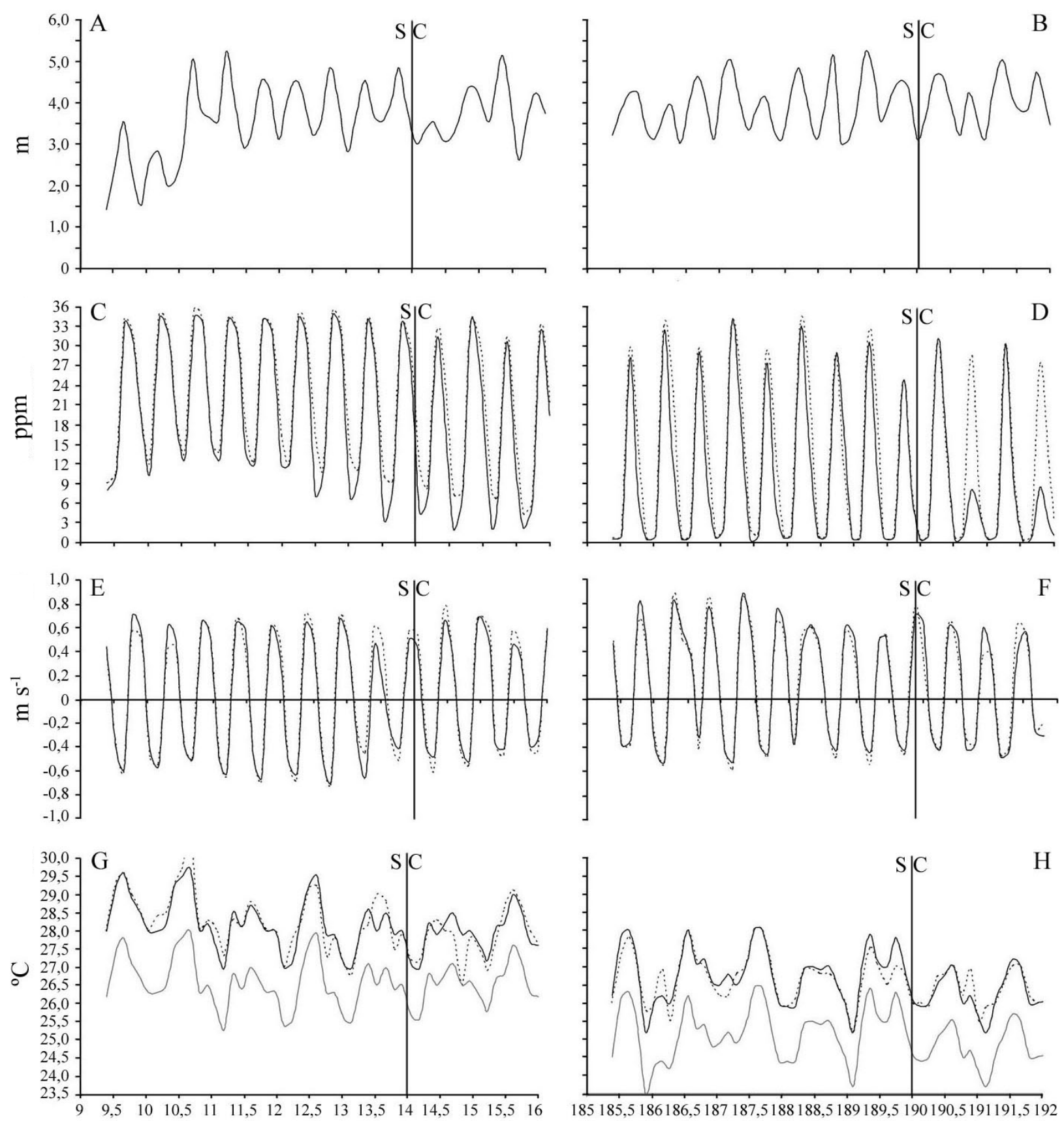

Días Julianos

Días Julianos

Figura 3

Serie temporal de: (A y B) profundidad local; (C y D) salinidad en la superficie (-) y en el fondo (- -); (E y F) velocidad de la corriente en la superficie (-) y en el fondo (- -) ; (G y H) temperatura del agua en la superficie (-), en el fondo (- -) y del aire (- gris). La línea vertical continua indica la separación entre los ciclos de marea de sicigia (S) y cuadratura (C). Los días julianos indican el periodo observado

Temporal series of: (A and B) local depth (-); (C and D) surface (-) and bottom salinities (- -); (E and F) current intensity, at surface $(-)$ and bottom $(--)$; (G and H) water temperature at surface $(-)$, bottom $(--)$ and of air (- gray). The vertical line indicates separation between spring (S) and neap (C) tidal cycles. The Julian days indicate the period observed 
estratificación vertical (Fig. 3c,d).

La intensidad de la corriente fue, en promedio, superior en enero, sin embargo, las mayores intensidades se registraron en julio. En este mes la intensidad media fue influenciada por un valor bajo $\left(0,06 \mathrm{~m} \mathrm{~s}^{-1}\right)$, registrado en la pleamar (Fig. 3e,f).

La amplitud promedio de la temperatura entre el verano (enero) y el invierno (julio) fue $1,51^{\circ} \mathrm{C}$, con un valor máximo en enero y un mínimo en julio (Fig. 3g,h). El valor medio obtenido para estos dos meses fue superior al histórico de $25,5^{\circ} \mathrm{C}$. El gráfico muestra la ausencia de
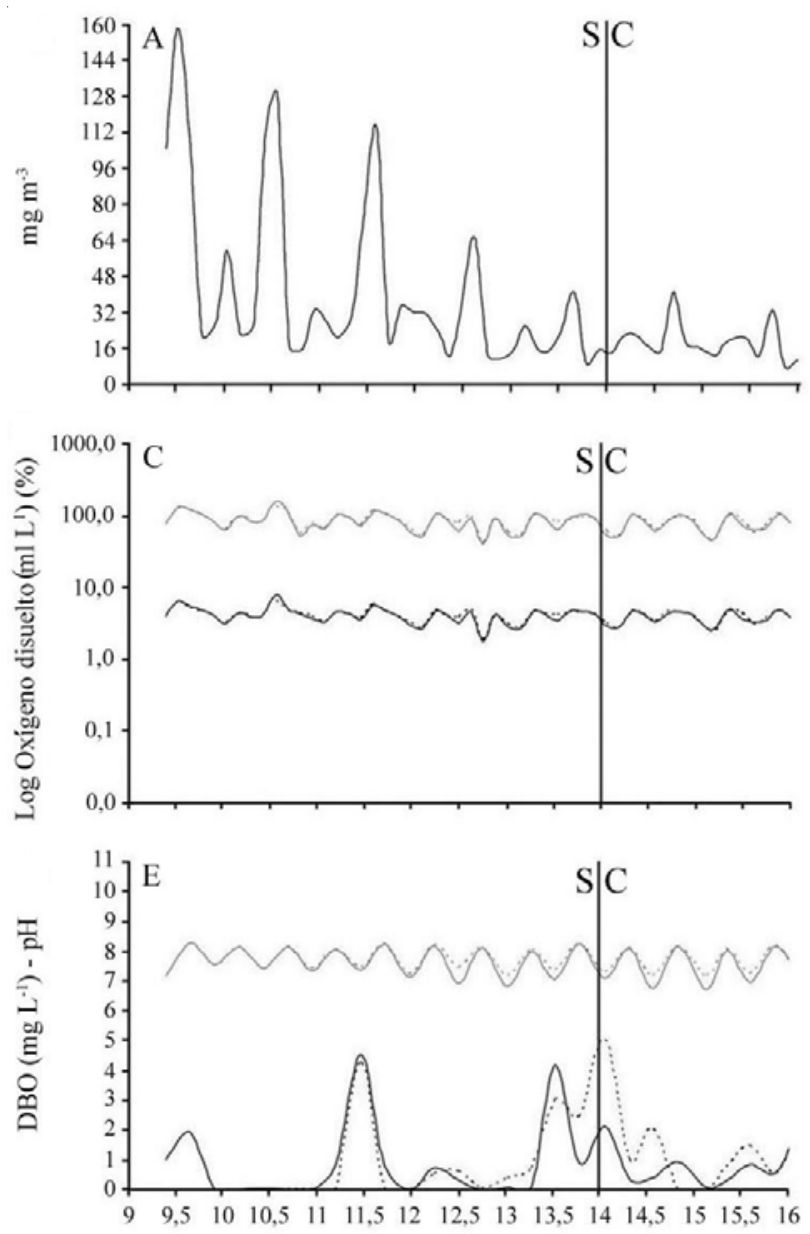

Días Julianos un gradiente vertical y, una variación regular entre el día y la noche, coincidiendo los bajos valores con las menores concentraciones de oxígeno disuelto, tanto en enero como en julio (Fig. 3g,h).

La variación temporal de la clorofila- $a$ fue mayor en enero, con valores medios y mínimos superiores a 20 y 7 $\mathrm{mg} \mathrm{m}^{-3}$ respectivamente durante los meses estudiados. El rango amplio durante el mes estival $(150,48)$ fue producto de valores superiores a $100 \mathrm{mg} \mathrm{m}^{-3}$ encontrados en este período (Fig. 4a,b).

El oxígeno disuelto mostró concentraciones mayores
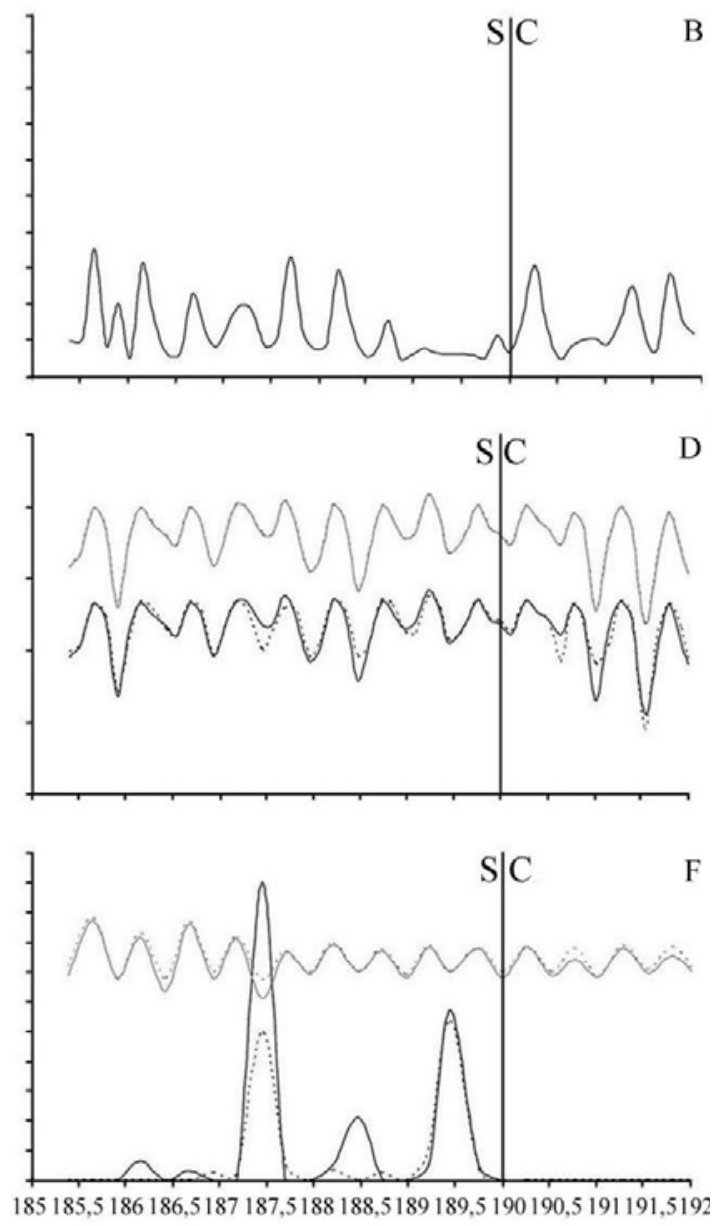

Días Julianos

Figura 4

Serie temporal de: (A y B) clorofila-a (-), en la superficie; (C y D) log oxígeno disuelto (-) y log tasa de saturación (- gris), en la superficie y en el fondo; (E y F) DBO (-) y pH (- gris). En la superficie (-) y en el fondo (- -). La línea vertical continua indica la separación entre los ciclos de marea de sicigia (S) y cuadratura (C). Los días julianos indican el periodo observado

Temporal series of: (A and B) Chlorophyll- $a(-)$, at surface; (C and D) log dissolved oxygen (-) and log saturation rate (- gray), at surface and bottom; (E and F) BOD (-) and $\mathrm{pH}$ (- gray). At surface (-) and bottom (- -). The vertical line indicates separation between spring $(\mathrm{S})$ and neap $(\mathrm{C})$ tidal cycles. The Julian days indicate the period observed 

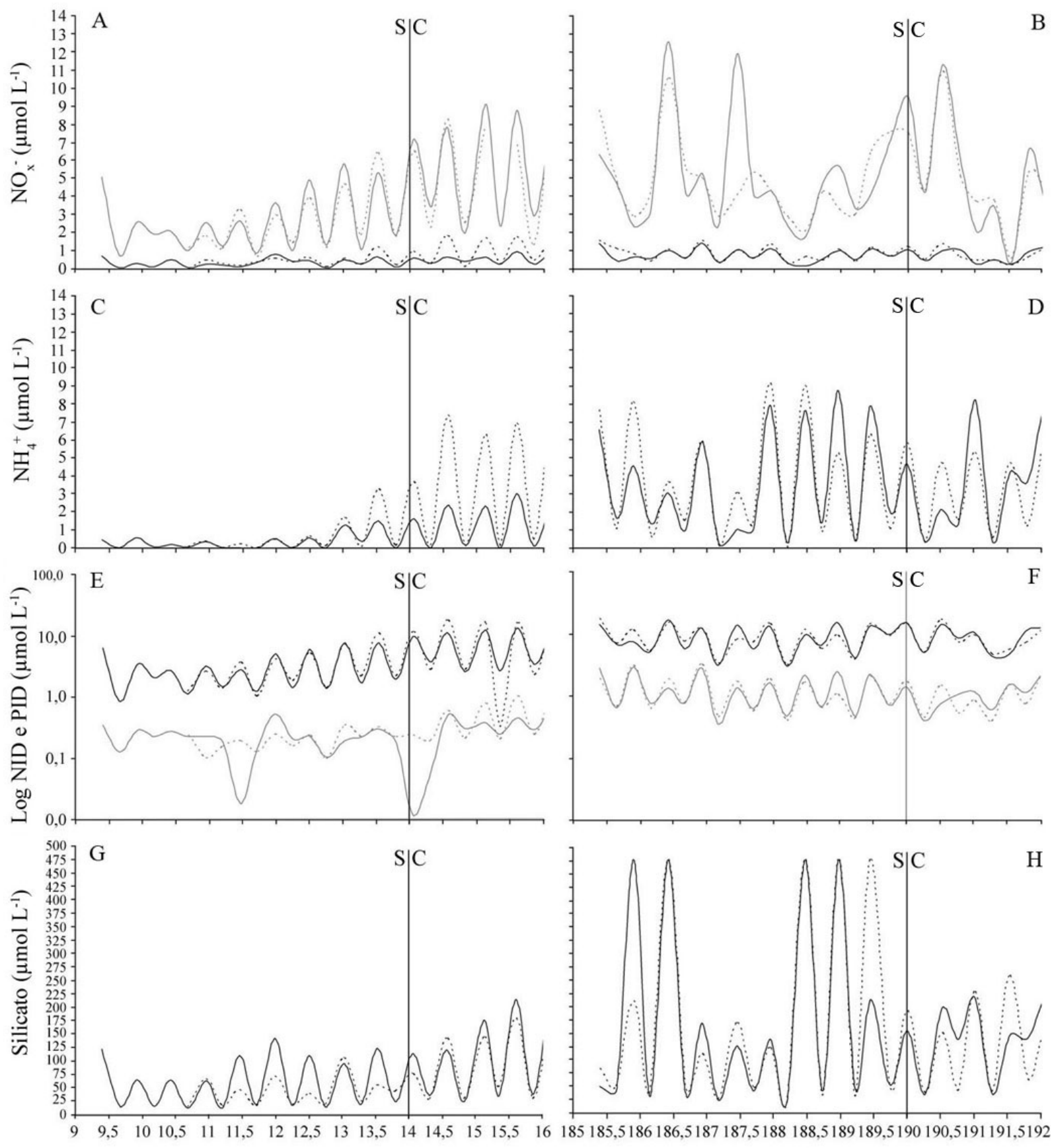

Días Julianos

Días Julianos

Figura 5

Serie temporal de: (A y B) compuestos nitrogenados, nitrato (- gris) y nitrito (-); (C y D) amonio; (E y F) log NID total (-), FID (- gris); (G y H) silicato. En la superficie (-) y en el fondo (- -). La línea vertical continua indica la separación entre los ciclos de marea de sicigia (S) y cuadratura (C). Los días julianos el periodo observado

Temporal series of: (A and B) nitrogen compounds, nitrate (- gray) and nitrite (-); (C and D) ammonia; (E and F) log total NID

$(-)$, total DIP (- gray); (G and H) silicate. At surface $(-)$ and bottom $(--)$. The vertical line indicates separation between spring $(\mathrm{S})$ and neap $(\mathrm{C})$ tidal cycles. The Julian days indicate period observed 
en enero cuando se registró un valor máximo de 7,96 mL $\mathrm{L}^{-1}$, y los menores en julio. La tasa de saturación del oxígeno disuelto varió de 1,44 a 160,37\%, entre julio y enero respectivamente (Fig. 4c,d).

La demanda bioquímica de oxígeno $\left(\mathrm{DBO}_{5}\right)$, registró valores bajos, siendo el máximo encontrado en julio (10,02 mg L-1), y mínimos en ambos períodos (Fig. 4e,f).

El pH presentó valores alcalinos y ácidos en ambos períodos, siendo registrado el valor de máxima alcalinidad en enero $(8,84)$ y el de máxima acidez en julio $(6,12)$ (Tabla 1, Fig. 4e,f).

La mayor concentración de DBO coincidió con el menor $\mathrm{pH}$ observado en julio, durante el horario diurno en el estadio de bajamar (Fig. 4f).

Los nutrientes nitrogenados registraron valores promedios mayores en julio, cuando el nitrato fue el compuesto que registró los valores medios y máximos mayores (Tabla 1, Fig. 5). El nitrito registró valores inferiores a $2 \mu$ moles $\mathrm{L}^{-1}$ durante todo el año, observándose picos durante la cuadratura de enero (Fig. 5a,b). El nitrato osciló entre pleamar y bajamar de forma ascendente durante enero; durante julio exhibió los mayores valores en las bajamares. El amonio, similar al nitrato, evidenció una oscilación ascendente en enero y altos valores en julio (Fig. 5c,d). Los valores totales (nitrito + nitrato + amonio) registrados en invierno fueron en promedio dos veces superiores aproximadamente a los del mes estival (Tabla 1, Fig. 5e,f).

Similar comportamiento registró el fosfato, siendo el promedio del mes estival cinco veces inferior al del mes invernal (Tabla 1, Fig. 5e,f). Las concentraciones en julio variaron fuertemente entre bajamar y pleamar, registrándose un valor máximo de 3,26 $\mu$ moles $\mathrm{L}^{-1}$; los valores mínimos de este período fueron equivalentes a los máximos de enero.

La relación de Redfield (N:P) mostró que, durante el período estival, la relación fue cuatro veces la del invierno (julio), registrándose relaciones de hasta 824:1 (enero). Esta relación muestra que en promedio durante el verano el fosfato fue el factor limitante y en julio fue el nitrógeno (Tabla 1).

El silicato fue el nutriente que registró las mayores concentraciones, con valores medios mayores en julio, y un valor máximo de 476,04 $\mu$ moles $\mathrm{L}^{-1}$. La amplitud media de este compuesto fue de $90 \mu$ moles $\mathrm{L}^{-1}$ entre enero y julio (Tabla 1, Fig. 5g,h).

\section{Diferencias entre día y noche}

Con el fin de estimar las influencias de la asimilación autotrófica sobre la disponibilidad de los nutrientes, fueron comparadas las concentraciones medias durante el día (05:00-18:00 h) en enero y en julio (05:30-17:30 h) y la noche en enero (19:00-04:00 h) y julio (18:0005:00 h).

Las diferencias observadas en las concentraciones evidenciaron poca amplitud entre el día y la noche para la salinidad $(\Delta=<6)$. El oxígeno disuelto siempre fue menor durante la noche en ambos meses. Entre los compuestos nitrogenados el amonio registró las mayores variaciones en relación a la noche $(\Delta=6-16)$. El fosfato fue menor al amonio con $\Delta=6-10$. El silicato y el nitrato mostraron variaciones diferentes entre enero y julio, durante el mes estival sus concentraciones fueron mayores a la noche, y en julio, lo fueron durante el día (Fig. 6).

\section{Análisis estadístico de las categorías y parámetros analizados}

Se encontraron diferencias estadísticamente significativas, según las pruebas F y t de Student $(\alpha=0,05)$, entre verano (enero) e invierno (julio) en: temperatura, salinidad, oxígeno disuelto, tasa de saturación, $\mathrm{pH}$, amonio, nitrito, fosfato, silicato, clorofila- $a$ y velocidad de la corriente (Tabla 2).

Para los períodos de sicigia y cuadratura, solo la temperatura, la salinidad y el nitrato mostraron diferencias de las medias $(\alpha=0,05)$.

Para los estadios de marea, todos los parámetros de la matriz mostraron diferencias significativas a excepción, de la temperatura, clorofila- $a$ y velocidad de la corriente $(\alpha=0,05)$.

Los gradientes verticales de los parámetros no presentaron diferencias estadísticamente significativas $(\alpha=0,05)$, lo que corrobora la homogeneidad de la columna de agua en el sistema.

Bajo el punto de vista diario (día y noche), la temperatura, el oxígeno disuelto, la tasa de saturación y, la clorofila- $a$ mostraron diferencias estadísticamente significativas $(\alpha=0,05)$.

Cuando la matriz de datos principal fue dividida y separada bajo los dos meses estudiados, los siguientes resultados fueron obtenidos: En enero y bajo la categoría de sicigia y cuadratura, todos los parámetros mostraron diferencias estadísticamente significativas a excepción de la DBO y el $\mathrm{pH}(\alpha=0,05)$, observación que no fue encontrada con la matriz principal. En la categoría de estadios de bajamar y pleamar, la temperatura mantuvo semejanza entre las medias y el nitrato no mostró diferencias significativas. Con el horario, nuevamente se 
Tabla 2

Análisis estadístico a través de las pruebas F y $\mathbf{t}$ de Student para las categorías. En negrita las medias que presentan diferencias significativas entre las categorías $(\alpha=0,05)$. Entre paréntesis los valores medios

F test and Student's t-test to the categories. In bold the means with significant differences (á $=0.05)$. Average values between brackets

\begin{tabular}{|c|c|c|c|c|c|}
\hline Parámetros & $\begin{array}{l}\text { Verano (enero) } \\
\text { Invierno (julio) }\end{array}$ & Sicigia / Cuadratura & $\begin{array}{l}\text { Bajamar / Pleamar } \\
\text { *llenante / vaciante }\end{array}$ & Superficie / Fondo & Día / Noche \\
\hline Temperatura & $(28,07-26,60)$ & $(27,48-27,01)$ & $(27,18-27,37)$ & $(27,35-27,31)$ & $(27,72-26,88)$ \\
\hline Salinidad & $(21,50-11,90)$ & $(18,13-13,56)$ & $(4,82-31,10)$ & $(14,29-16,14)$ & $(16,95-16,23)$ \\
\hline Oxígeno disuelto & $(4,07-2,80)$ & $(3,55-3,17)$ & $(2,16-4,65)$ & $(3,34-3,29)$ & $(3,64-3,18)$ \\
\hline $\mathrm{DBO}_{5}$ & $(0,90-0,57)$ & $(0,81-0,58)$ & $(1,20-0,42)$ & $(0,80-0,77)$ & $(0,97-0,47)$ \\
\hline $\mathrm{pH}$ & $(7,78-7,37)$ & $(7,57-7,45)$ & $(7,01-8,08)$ & $(7,39-7,51)$ & $(7,59-7,46)$ \\
\hline Amonio & $(0,95-3,50)$ & $(2,27-2,49)$ & $(4,19-0,51)$ & $(2,32-2,94)$ & $(2,04-2,64)$ \\
\hline Nitrito & $(0,44-0,81)$ & $(0,63-0,69)$ & $(0,88-0,37)$ & $(0,62-0,74)$ & $(0,62-0,67)$ \\
\hline Nitrato & $(3,85-5,32)$ & $(4,12-5,89)$ & $(5,52-3,55)$ & $(4,67-5,25)$ & $(4,70-4,52)$ \\
\hline Fosfato & $(0,26-1,31)$ & $(0,90-0,68)$ & $(1,19-0,39)$ & $(0,88-0,92)$ & $(0,72-0,95)$ \\
\hline Silicato & $(59,20-135,17)$ & $(99,68-103,18)$ & $(188,70-34,02)$ & $(116,86-109,71)$ & $(94,98-106,74)$ \\
\hline Clorofila- $a$ & $(34,04-20,85)$ & $(30,21-20,81)$ & $(26,23-26,27)$ & $(27,38)-$ & $(33,80-20,31)$ \\
\hline \multirow[t]{2}{*}{ Veloc. corriente } & $(0,53-0,45)$ & $(0,51-0,43)$ & $\begin{array}{r}(0,46-0,49) \\
*(0,38-0,66)\end{array}$ & $(0,50-0,48)$ & $(0,49-0,49)$ \\
\hline & \multicolumn{5}{|c|}{ Enero (Verano) } \\
\hline Temperatura & - & $(28,26-27,74)$ & $(28,04-28,05)$ & $(28,09-28,10)$ & $(28,39-27,67)$ \\
\hline Salinidad & - & $(23,96-16,75)$ & $(9,54-33,57)$ & $(19,15-21,17)$ & $(20,85-22,37)$ \\
\hline Oxígeno disuelto & - & $(4,24-3,75)$ & $(3,27-4,51)$ & $(4,02-4,03)$ & $(4,38-3,67)$ \\
\hline $\mathrm{DBO}_{5}$ & - & $(0,82-1,06)$ & $(1,41-0,57)$ & $(0,88-1,11)$ & $(0,98-0,81)$ \\
\hline $\mathrm{pH}$ & - & $(7,84-7,64)$ & $(7,18-8,16)$ & $(7,63-7,77)$ & $(7,82-7,71)$ \\
\hline Amonio & - & $(0,32-2,11)$ & $(2,27-0,08)$ & $(0,68-1,68)$ & $(0,92-0,99)$ \\
\hline Nitrito & - & $(0,30-0,69)$ & $(0,78-0,21)$ & $(0,40-0,58)$ & $(0,45-0,43)$ \\
\hline Nitrato & - & $(2,21-6,90)$ & $(5,51-2,75)$ & $(3,63-5,21)$ & $(4,10-3,50)$ \\
\hline Fosfato & - & $(0,20-0,38)$ & $(0,38-0,18)$ & $(0,25-0,32)$ & $(0,25-0,28)$ \\
\hline Silicato & - & $(42,42-90,46)$ & $(114,70-22,68)$ & $(75,62-59,18)$ & $(53,75-66,95)$ \\
\hline Clorofila- $a$ & - & $(41,00-18,81)$ & $(39,70-17,41)$ & $(34,04)$ & $(44,24-21,63)$ \\
\hline \multirow[t]{2}{*}{ Veloc. corriente } & - & $(0,55-0,49)$ & $(0,50-0,56)$ & $(0,54-0,52)$ & $(0,51-0,54)$ \\
\hline & & & $*(0,41-0,64)$ & & \\
\hline \multicolumn{6}{|c|}{ Julio (Invierno) } \\
\hline Temperatura & - & $(26,76-26,25)$ & $(26,41-26,66)$ & $(26,61-26,57)$ & $(26,96-26,25)$ \\
\hline Salinidad & - & $(12,65-10,29)$ & $(0,61-28,50)$ & $(9,42-11,39)$ & $(12,52-11,29)$ \\
\hline Oxígeno disuelto & - & $(2,90-2,58)$ & $(1,17-4,79)$ & $(2,66-2,58)$ & $(2,81-2,79)$ \\
\hline DBO & - & $(0,80-0,003)$ & $(1,01-0,24)$ & $(0,73-0,47)$ & $(0,96-0,20)$ \\
\hline $\mathrm{pH}$ & - & $(7,39-7,32)$ & $(6,86-8,00)$ & $(7,23-7,36)$ & $(7,40-7,34)$ \\
\hline Amonio & - & $(3,70-2,91)$ & $(5,91-0,98)$ & $(3,70-3,88)$ & $(3,27-3,67)$ \\
\hline Nitrito & - & $(0,86-0,68)$ & $(0,97-0,55)$ & $(0,81-0,87)$ & $(0,80-0,82)$ \\
\hline Nitrato & - & $(5,52-4,77)$ & $(5,53-4,40)$ & $(5,54-5,27)$ & $(5,53-5,16)$ \\
\hline Fosfato & - & $(1,41-1,02)$ & $(1,92-0,60)$ & $(1,41-1,38)$ & $(1,24-1,36)$ \\
\hline Silicato & - & $(141,60-117,68)$ & $(254,85-46,00)$ & $(151,65-147,61)$ & $(139,86-131,38)$ \\
\hline Clorofila- $a$ & - & $(20,00-22,94)$ & $(12,75-34,45)$ & $(20,85)$ & $(22,56-19,14)$ \\
\hline \multirow[t]{2}{*}{ Veloc. corriente } & - & $(0,48-0,37)$ & $(0,43-0,41)$ & $(0,45-0,44)$ & $(0,45-0,44)$ \\
\hline & & & $*(0,35-0,68)$ & & \\
\hline
\end{tabular}




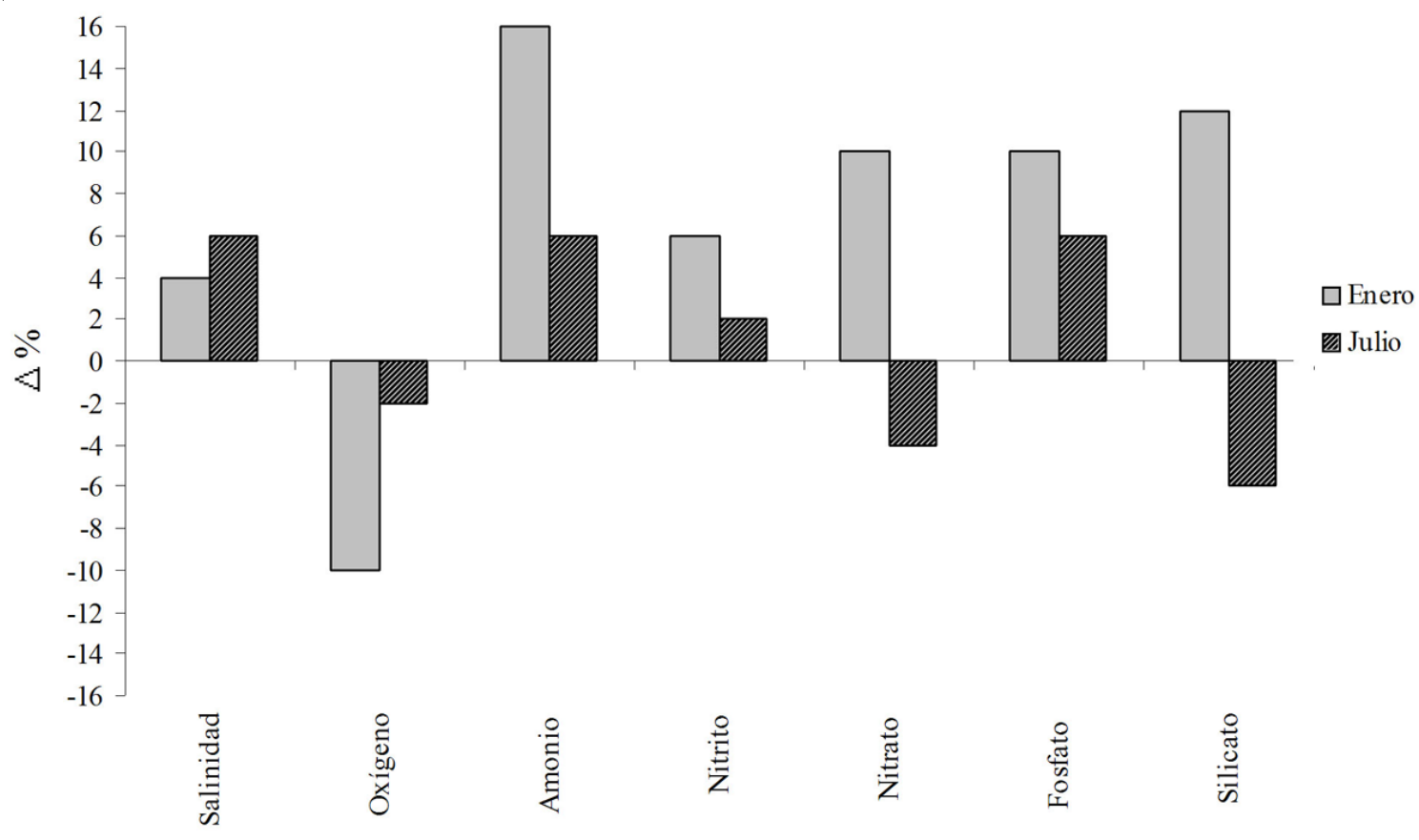

Figura 6

Concentraciones medias de consumo en relación a la noche $(\Delta \%)$

Average consumption in the day in relation to night $(\Delta \%)$

encontraron diferencias significativas para la temperatura, oxígeno disuelto, tasa de saturación y clorofila- $a$.

En julio (invierno), los parámetros mostraron mayores cambios con respecto a la matriz principal, durante las categorías de sicigia-cuadratura y horario (día y noche).

En la categoría sicigia y cuadratura y, horario diurno y nocturno, solo la temperatura mostró diferencias estadísticamente significativas $(\alpha=0,05)$. En esta categoría, la velocidad de la corriente también mostró una variación significativa entre enero y julio (Tablas 1 y 2), las velocidades en sicigia siempre fueron mayores (Tabla 1). En las categorías analizadas fueron considerado también los estadios de flujo y reflujo, donde fueron observadas variaciones, principalmente en julio, cuando la amplitud fue mayor $\left(\Delta=-0,33 \mathrm{~m} \mathrm{~s}^{-1}\right)$ (Tabla 2). En todas las condiciones analizadas la categoría reflujo fue mayor que la categoría flujo (Fig. 3c,d).

Así como en los análisis anteriores la categoría de estadios de marea fue la que mostró las mayores desigualdades entre sus medias aritméticas, en enero (verano), la mayoría de los parámetros mostraron diferencias estadísticamente significativas excepto la temperatura, DBO, nitrato y la intensidad de la corriente en bajamar y pleamar.

En la categoría horario, solo la temperatura mostró diferencias estadísticamente significativas entre el día y la noche.

La Fig. 7 muestra el plano factorial de los factores 1 y 2, obtenidos en el ACP. Las dos primeras componentes (PC1 e PC2) explicaron el 83,22\% de la varianza total. La primera componente (PC1) explicó el 68,30\% de la varianza total, siendo formada, en su lado negativo, por el oxígeno disuelto, salinidad y $\mathrm{pH}$, asociados al mes de enero y a la pleamar. En la extremidad positiva, se destacan los nutrientes inorgánicos nitrogenados, fosfato y el silicato, asociados al mes de julio y bajamar. El eje 2 fue formado por la clorofila- $a$ y temperatura en la extremidad positiva y, profundidad local en la extremidad negativa y explicó el 14,91\% de la variancia. La DBO, velocidad de la corriente y relación N:P no mostraron 


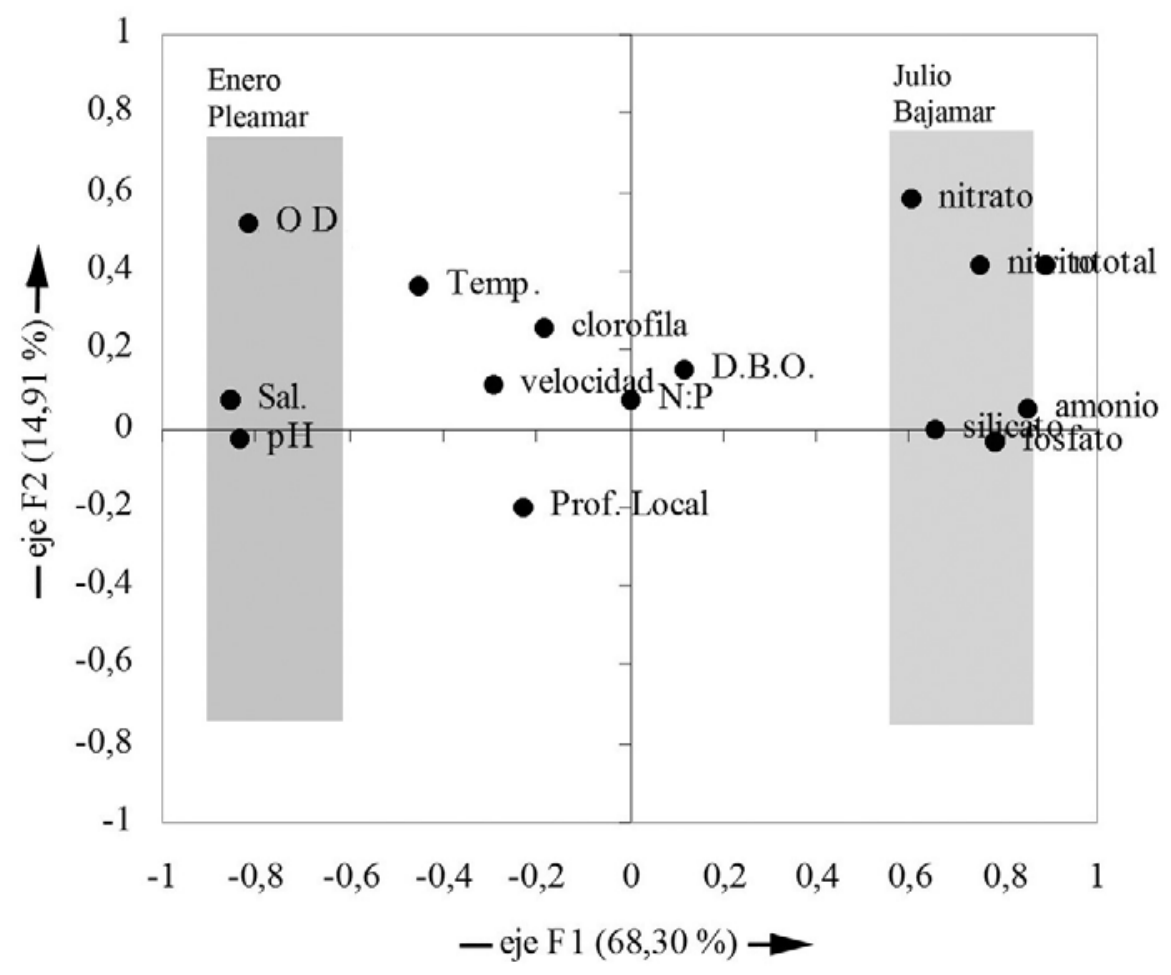

Figura 7

\section{Plano factorial formado por los factores 1 y 2, obtenidos a partir del análisis de componentes principales} hecho sobre los datos de enero y julio

Factorial plans formed by axis 1 and 2, obtained from Principal Components Analysis January and July data

influencia en estos dos factores.

\section{Discusión}

A través del análisis estadístico, se determinaron diferencias significativas entre los períodos estudiados, demostrando la gran influencia y variabilidad de las mareas y de la descarga fluvial en los procesos estuarinos tropicales.

Durante el mes estival, la tasa de evaporación, corrientes de mareas y, en menor escala, los vientos fueron mayores, definiendo valores mayores de parámetros como temperatura, salinidad, oxígeno disuelto, $\mathrm{pH}$, clorofila$a$. Por otro lado, se caracterizaron menores valores en la intensidad de las corrientes, DBO y nutrientes.

Esta estacionalidad está bien definida para un área tropical, hecho registrado por Branco et al. (2002) en este estuario entre 1999 y 2000, Flores Montes (1996), en el Canal de Santa Cruz y, por Macêdo \& Costa (1990) en el estuario del Río Igarassú.
Las diferencias entre sicigia y cuadratura de la temperatura durante los meses observados ocurrieron probablemente debido a las variaciones en la intensidad de los vientos durante los días de muestreo, cuando las intensidades fueron siempre mayores en cuadratura, produciendo una transferencia mayor de la cantidad de movimiento del aire al agua, asociada a una área de poca profundidad, hecho demostrado por la ausencia de estratificación térmica.

Los valores salinos más elevados en los períodos de sicigia están sustentados por la influencia de las corrientes de marea, que en este período son más intensas, disminuyendo la cantidad de agua dulce retenida en el área, y al mayor volumen de agua marina. En la cuadratura, los menores valores demostraron que la influencia fluvial es más notoria. La variación nictimeral fue bien definida, acompañando el ciclo de las mareas, con valores mayores en las pleamares. La estratificación salina en la estación de muestreo no mostró diferencias significativas y, las variaciones menores a 3 unidades salinas entre superficie y el fondo indicaron un área verticalmente homogénea. Durante el mes estival 
observado, las corrientes de marea también influenciaron las mayores concentraciones de oxígeno disuelto y la oxigenación relativa, así como el pH y nutrientes, caracterizando el área como supersaturada en relación al porcentaje de oxígeno en la mayoría de los estadios de marea, independientemente del horario de muestreo; este hecho quedó demostrado con los valores de oxígeno disuelto en las pleamares en el horario nocturno. La oxigenación del medio y porcentaje de saturación fueron atribuibles a la hidrodinámica del período de sicigia que otorgó características de un ambiente que se renueva constantemente. Esta oxigenación se relacionó directamente al ciclo de los nutrientes nitrogenados, cuando las concentraciones de amonio fueron bajas en el área de estudio durante enero, evidenciando el proceso de nitrificación completa de este elemento, resultante de la descomposición de la materia orgánica. Esto se demuestra al observar las concentraciones del nitrito, más bajas que las de nitrato. Según Day et al. (1989), las concentraciones de cada uno de los nutrientes nitrogenados son fuertemente influenciadas por el ciclo dinámico del oxígeno del medio. Las condiciones favorables para el fitoplancton en este período, respecto a la disponibilidad de nutrientes, luz y transparencia de la columna de agua, contribuyeron al aumento de su biomasa, mostrando altas concentraciones de clorofila$a$, caracterizando el ambiente como eutrófico según la clasificación de Tundisi \& Tundisi (1976), principalmente en las mareas de bajamar y durante el horario diurno.

En el nivel de cuadratura, las condiciones variaron, evidenciando mayores concentraciones de amonio, así como también de nitrito y nitrato, sin embargo, aún sobre condiciones de nitrificación, de acuerdo con los registros en las concentraciones de oxígeno disuelto y tasas de saturación. Las lluvias caídas al final de la sicigia pudieron ser las causas de esta variación, hecho demostrado por el aumento en las intensidades de las mareas de reflujo en este periodo, lo que pudo generar un aumento en la carga de nutrientes para el estuario. En bajamar fueron observadas las mayores concentraciones de estos elementos durante los dos meses, indicando la influencia de los ríos en el aporte del nitrógeno, lo cual es evidente al observar los picos de la biomasa fitoplanctónica en estas mareas.

Durante este período, el horario mostró que el amonio decrece durante la noche en mayor porcentaje que el nitrito y el nitrato se mostró con porcentajes inversos en relación a este factor, indicando que el amonio sería el compuesto nitrogenado asimilado por los organismos fitoplanctónicos durante ambos períodos. El amonio es generalmente un nutriente importante debido a su carácter limitante para el crecimiento del fitoplancton. Day et al.
(1989) y Koroleff (1983), citan una concentración de 5 ì mol L ${ }^{-1}$ de amonio como normal en ambientes estuarinos sin contaminación.

La estacionalidad mostrada por el fosfato en el presente trabajo difiere de estudios previos, como los de Branco et al. (2002) y Okuda et al. (1960b). Las bajas concentraciones observadas durante enero (un valor sobre 1,0 ìmol L ${ }^{-1}$ ) indican la actividad consumidora por parte del fitoplancton, cuando el fósforo presenta un comportamiento limitante para el crecimiento de la biomasa fitoplanctónica, con relaciones N:P (Relación de Redfield) de 20:1. En estuarios sin contaminación, las concentraciones normalmente varían en torno a 0,025 mg $\mathrm{L}^{-1}$ (cerca de 0,81 ìmol L-1) (Baumgarten \& Pozza 2001). La máxima concentración de fosfato según Liss (1976) no debe ser superior a 1,2 ìmol $\mathrm{L}^{-1}$ o 1,0 ìmol L L ${ }^{-1}$ según Aminot \& Chaussepied (1983).

Durante este período la DBO presentó bajas concentraciones en relación a otras áreas estuarinas tropicales, indicativas de menor cantidad de materia orgánica biodegradable en el medio.

Durante el invierno, la situación en relación a la contaminación orgánica fue crítica (porcentajes menores a 50\% de oxígeno), sin embargo, los valores de DBO no fueron indicadores de esta situación. Las bajas concentraciones de oxígeno disuelto y porcentajes de saturación, contrastaron con altas concentraciones de compuestos nitrogenados y fosfatados. Es posible que los procesos de biodegradación ocurrieran a lo largo de los ríos, llegando esa materia orgánica a la zona de confluencia totalmente mineralizada.

Las altas concentraciones registradas en invierno, tanto en el período de sicigia como de cuadratura, son indicativas de un incremento en los aportes antropogénicos directos e indirectos, influenciados por el aumento en la descarga de los ríos producto de las mayores precipitaciones (corrientes mayores en vaciante). Esta diferencia estacional, puede estar asociada también a los menores niveles de actividad biológica durante esta época (ver clorofila- $a$ ), producto del mayor aporte de material en suspensión, reduciendo la penetración de la luz en la columna de agua (Fig. 3b), indicando que el proceso de amonificación es intenso en el área.

Las concentraciones de nitrato no mostraron una variación significativa entre enero y julio. A diferencia de los otros compuestos inorgánicos nitrogenados, el nitrato mostró siempre concentraciones inferiores a las especificadas por Aminot \& Chaussepied (1983) (1-15 ìmol L ${ }^{-1}$ ). Según Carmouze (1994), la velocidad de regeneración o formación del nitrato es, en general, menor 
que la de asimilación por los productores primarios, resultando en bajas concentraciones de nitrato en la columna de agua.

En julio, el proceso de nitrificación indicó alteraciones, mostrando una mudanza en la secuencia de las concentraciones del ciclo del nitrógeno para $\mathrm{NH}_{4}^{+}>\mathrm{NO}_{3}^{-}>\mathrm{NO}_{2}^{-}$, tanto en la sicigia como en la cuadratura. Esto mostró una reducción en la calidad de las aguas, producto de las condiciones climáticas acompañadas del aporte de desechos domésticos e industriales ricos en compuestos nitrogenados. Similares resultados fueron observados para los meses lluviosos y en las bajamares por Branco et al. (2002) y Okuda et al. (1960b) en esta área, Santos et al. (2000) en el estuario del Río Jaguaribe y Flores Montes et al. (2002) en el Canal de Santa Cruz.

El fósforo es casi ausente en la atmósfera, y la única adición relevante de este elemento en el océano proviene del agua de río (Tyrrell 1999).

Las altas concentraciones de este elemento durante julio se suman a los compuestos nitrogenados, siendo probable que la fuente principal sea la meteorización de los minerales de la corteza terrestre a través de los ríos como vía de transporte, asociada al aumento en las precipitaciones. Las características físicas del suelo (mangue) de este tipo de ecosistema compuesto de material arcilloso, limo, arena y lodo favorecerían la suspensión de los fosfatos contenidos en el agua intersticial de la columna sedimentaria. Debido a estos procesos, la relación N:P en el mes invernal acusaría una disminución en relación al mes estival. Según Conley (2000), en los últimos años, varios estudios demostraron que la alternancia en el nutriente limitante es una característica común en todos los estuarios.

El óxido de silicio es conocido por ser una parte esencial en las estructuras sólidas de los silicoflagelados, diatomeas, algunos radiolarios y esponjas. En zonas costeras y en regiones estuarinas las concentraciones varían próximas a $150 \mathrm{ìmol} \mathrm{L} \mathrm{L}^{-1}$, llegando hasta 200 ìmol L ${ }^{-1}$ (Millero \& Sohn 1996). Según Maybeck (1979), el silicio disuelto es el mayor constituyente en el agua de río, representando un $10 \%$ del total de sólidos disueltos, y su media global de concentración ha sido estimada en 4,85 $\mathrm{mg} \mathrm{L}^{-1}$ (cerca de 80,83 ìmol L ${ }^{-1}$ ).

Las altas concentraciones de silicato observadas en el invierno, confirmarían la naturaleza terrígena de este nutriente con la ayuda de las lluvias y drenaje terrestre. Durante el verano, y bajo la influencia del período de sicigia, se observaron concentraciones menores de 150 ìmol $\mathrm{L}^{-1}$, con valores próximos a los especificados por
Maybeck (1979). Sin embargo, los valores registrados son mayores a los observados por Branco et al. (2002). Las concentraciones durante el invierno sobrepasan la media citada por De Master et al. (1983) (135 ìmol L-1) y Santos (2000) (108,19 ìmol L-1), para la desembocadura del río Amazonas. Lacerda (2004), durante 2001, en Barra de Jangadas, observó que la comunidad fitoplanctónica estuvo caracterizada en ambos períodos del año por las diatomeas, representando casi el 50\% del total de los grupos identificados, siendo las especies mas abundantes: Cyclotella meneghiniana Kützing, en enero y Oscillatoria sp. en julio. Cyclotella meneghiniana, Bacillariophyceae, fue registrada en todas las mareas, en virtud de su carácter eurihalino y es característica de regiones productivas (Grego 2004). Oscillatoria sp., es una especie característica de agua dulce, sin embargo, posee la capacidad de adaptarse fisiológicamente en aguas salobres y eutróficas. Según Grego (2004), en la división Cyanophyta existen ciertas especies como Oscillatoria sp., bioindicadoras de áreas con elevadas concentraciones de materia orgánica, siendo este taxón el que tolera en mayor magnitud la contaminación orgánica.

Las mediciones entre día y noche de los nutrientes, oxígeno y salinidad indicaron que la salinidad varía poco entre el día y la noche, y que la influencia de la evaporación sobre el cuerpo de agua no es significativamente mayor durante el día. En la estación de muestreo, las concentraciones de oxígeno disuelto $(\Delta$ $\%=-10 \mathrm{y}-2$ ), fueron menores durante la noche, indicando que la actividad fotosintética es mayor en enero. El gran contraste fue observado para el amonio, con una diferencia día/noche de $16 \%$ en enero, el cual parece ser el compuesto asimilado por los organismos autotróficos en esa época del año. Otros compuestos nitrogenados y el fosfato mostraron diferencias $<10 \%$ entre ambos periodos.

El nitrato y el silicato durante el mes invernal, mostraron un comportamiento inverso en relación a los demás compuestos analizados, siendo probable que el nitrato y el silicato sean condicionados por la lluvia contribuyendo al enriquecimiento de los nutrientes para el estuario vía descarga fluvial, no siendo asimilados directamente por los organismos fitoplanctónicos durante el día.

Las diferencias entre los meses fueron demostrados a través del ACP, como también entre los estadios de marea y parámetros asociados. Así, parámetros como las sales nutrientes mostraron una correlación con el estadio de bajamar, indicativo de contaminación de origen doméstico y/o industrial. El eje 2 de ese análisis asoció procesos como la productividad primaria a través de la directa 
relación entre temperatura y clorofila- $a$ en oposición a la profundidad local.

\section{Agradecimientos}

Los autores agradecen el soporte financiero concedido por CNPq (Conselho Nacional de Desenvolvimento Científico do Brasil). Extendemos nuestros agradecimientos a los evaluadores, que colaboraron eficazmente con sugerencias y críticas constructivas para la finalización de este trabajo.

\section{Literatura citada}

Aminot A \& M Chaussepied. 1983. Manuel des analyses chimiques en milieu marin, 395 pp. CNEXO, Brest.

APHA. 1985. Standards methods for the examination of wastewater, 1268 pp. American Public Health Association, New York.

Araujo M, C Medeiros \& C Ribeiro. 1999. Energy balance and time-scales of mixing and stratification in the Jaboatão estuary, Brazil. Revista Brasileira de Oceanografia 47(2): 145-154.

Baumgarten MGZ \& SA Pozza. 2001. Qualidade de águas: descrição de parâmetros químicos referidos na legislação ambiental, 166 pp. Fundação Universidade Federal do Rio Grande, Rio Grande.

Braga ES, CVD Bonetti, L Burone \& J Bonetti-Filho. 2000. Eutrophication and bacterial pollution caused by industrial and domestic wastes at the Baixada Santista estuarine system - Brazil. Marine Pollution Bulletin 40(2): 165-173.

Branco ES, FAN Feitosa \& MJ Flores-Montes. 2002. Variação sazonal e espacial da biomassa fitoplantónica relacionada com parâmetros hidrológicos no estuário de Barra de Jangadas (Jaboatão dos Guararapes-Brasil). Tropical Oceanography 30(2): 79-96.

Carmouze JP. 1994. O metabolismo dos ecossistemas aquáticos: Fundamentos teóricos, métodos de estudos e análises químicas, 254 pp. Edgard Blücher. FAPESP, São Paulo.

Coutinho PN. 1997. Estudo da erosão marinha nas praias de Piedade, Candeias e no estuário de Barra de Jangadas. Relatório, 60 pp. Editora da UFPE, Recife.

Conley DJ. 2000. Biogeochemical nutrient cycles and nutrient management strategies. Hydrobiologia 410: 87-96.

CPRH. 2001. Planilhas de Controle industrial do Estado, 100 pp. Companhia Pernambucana de Controle da Poluição e Recursos Hídricos, Recife.

Day JR, CA Hall, WM Kemp \& A Yañez-Arancibia. 1989. Estuarine ecology, 558 pp. John Wiley \& Sons, New York.

De Master DJ, GB Knapp \& CA Nittrover. 1983. Biological uptake and accumulation of silica on the Amazon continental shelf. Geochimica et Cosmochimica Acta 47(1): 1713-1723.
Flores Montes MJ. 1996. Variação nictemeral do fitoplâncton e parâmetros hidrológicos no canal de Santa Cruz, Itamaracá, Brasil. Tese em Oceanografia, Centro de Tecnologia e Geociências, Universidade Federal de Pernambuco, Recife, 199 pp.

Flores Montes MJ, SJ Macêdo \& ML Köening. 2002. N:S:P atomic ratio in the Santa Cruz Channel, Itamaracá - PE (Northeast Brazil): a nyctemeral variation. Brazilian Archives of Biology and Technology 45(2): 115-124.

Grasshoff K, K Kremling \& M Ehrhardt. 1983. Methods of seawater analysis, 317 pp. Wiley-Verlag Chemie, New York.

Grego CKS. 2004. Distribuição espacial e sazonal da composição e biomassa fitoplantónica correlacionada com a hidrologia do estuário de Rio Timbó (Paulista-PE). Dissertação em Oceanografia, Centro de Tecnologia e Geociências, Universidade Federal de Pernambuco, Recife, 117 pp.

Instituto Brasileiro de Geografia e Estatística. 2000. Censo 2000 da população brasileira. [en línea]. Disponible en: http://www.Ibge.gov.br.

Koroleff F. 1983. Determination of ammonia. En: Grasshoff K, K Kremling \& M Ehrhardt (eds). Methods of seawater analysis, pp. 150-157. Wiley-Verlag Chemie, New York.

Lacerda SR. 2004. Série temporal do fitoplâncton no estuário de Barra de Jangadas (Jaboatão dos Guararapes - Brasil). Tese em Oceanografia, Centro de Tecnologia e Geociências, Universidade Federal de Pernambuco, Recife, 196 pp.

Liss PS. 1976. Conservative and non conservative behavior of dissolved constituents during estuarine mixing. En: Burton JD \& PS Liss (eds). Estuarine chemistry 4: 93-127. Academic Press, London.

Macêdo SJ \& KMP Costa. 1990. Condições hidrológicas do estuário do Rio Igarassu-Itamaracá-PE. Trabalhos Oceanográficos 21: 7-32.

Massart DL. 1998. Handbook of chemometrics and qualimetrics, 593 pp. Elsevier, Amsterdam.

Maybeck M. 1979. Concentrations des eaux fluviales en éléments majeurs et apports en solution aux océans. Revue de Géologie Dynamique et Geographie Physique 21: 215246.

Millero FJ \& ML Sohn. 1996. Chemical oceanography, 531 pp. CRC Press, Boca Raton.

Noriega CD, K Muniz, MC Araujo, RK Travassos \& S Neumann-Leitão. 2005. Fluxo de nutrientes inorgânicos dissolvidos em um estuário tropical - Barra das Jangadas PE, Brasil. Tropical Oceanography 33(2): 129-139.

Okuda T \& R Nobrega. 1960. Estudo da Barra das Jangadas. Parte 1. Distribuição e movimento da clorinidade quantidade de corrente. Trabalhos Oceanográficos 2(1): 175-191.

Okuda T, L Cavalcante \& MP Borba. 1960b. Estudo da Barra das Jangadas. Parte 3. Variação do nitrogênio e fosfato durante o ano. Trabalhos Oceanográficos 2(1): 207-218. 
Peel, MC, BL Finlayson \& TA McMahon. 2007. Updated world map of the Updated world map of the Köppen-Geiger climate classification. Hydrology and Earth System Sciences 11: 1633-1644.

Pereira-Filho J, LC Spillere \& CAF Schettini. 2003. Dinâmica de nutrientes na região portuária do estuário do Rio Itajaí - Açu, SC. Atlântica 25(1): 11-20.

Santos L. 2000. Influência dos Rios Amazonas e Pará sobre a biomassa fitoplanctónica. Tese em Oceanografia, Centro de Tecnologia e Geociências, Universidade Federal de Pernambuco, Recife, 92 pp.

Santos-Fernandes TL, JZO Passavante, ML Koening, SJ Macêdo \& IC Lins. 2000. Fitoplâncton do estuário do Rio Jaguaribe, (Itamaracá, Pernambuco, Brasil): Produção e hidrologia. Revista de Ecologia Aquática Tropical 10: 4369.

Strickland JDH \& TR Parsons. 1965. A manual of seawater analysis. Bulletin of the Fisheries Research Board of Canada 125: 1-205.
Strickland JDH \& TR Parsons. 1972. A practical handbook of seawater analysis. Bulletin of the Fisheries Research Board of Canada 167: 1-211.

Texeira C. 1973. Introdução aos métodos para medir a produção primária do fitoplâncton marinho. Boletim do Instituto Oceanográfico da Universidade de São Paulo 22: 59-92.

Tundisi JG \& TM Tundisi. 1976. Produção orgânica em ecossistemas aquáticos. Ciência e Cultura 28(8): 864-87.

Tyrrell T. 1999. The relatives influence of nitrogen and phosphorous on oceanic primary production. Nature 400 : 525-531.

UNESCO. 1986. International Oceanographic Tables, vol. 4. UNESCO, Technical Papers in Marine Science 40: 1-193.

Recibido el 1 de agosto de 2008 y aceptado el 24 de noviembre de 2008 